\title{
Effects of High-Intensity Long-Duration Continuous AE Activity in the Equatorial Ionosphere Dynamics
}

José Humberto Andrade Sobral, Mangalathayil Ali Abdu, Walter Demetrio González, Alicia Clua de Gonzalez Instituto Nacional de Pesquisas Espaciais- INPE, Brazil, B. Tsurutani Jet Propulsion Laboratory, Pasadena, U. S. A., Inez Staciarini Batista, Isabela Galvão Barbosa, Renato Ribeiro Lira da Silva, Daniela Cristina Santana Arruda, Carlos José Zamlutti , C. M. Denardini, Fernando Guarnieri INPE

Copyright 2005, SBGf - Sociedade Brasileira de Geofísica

This paper was prepared for presentation at the $9^{\text {th }}$ International Congress of the Brazilian Geophysical Society held in Salvador, Brazil, 11-14 September 2005.

Contents of this paper were reviewed by the Technical Committee of the $9^{\text {th }}$ International Congress of the Brazilian Geophysical Society. Ideas and concepts of the text are authors' responsibility and do not necessarily represent any position of the text are authors' responsibility and do not necessarily represent any position of the
SBGf, its officers or members. Electronic reproduction or storage of any part of this paper for commercial purposes without the written consent of the Brazilian Geophysical Society is prohibited.

\section{Abstract}

The High Intensity Long-Duration Continuous AE Activity - HILDCAAs are continuous activity of high intensity auroral currents for days or weeks, in the absence of geomagnetic storms. The HILDCAAs effects on the low latitude ionosphere are not very well known since they have not been experimentally studied in detail. In this work we analyze the responses of the equatorial ionosphere over the Brazilian region to intense episodes of High Intensity Long-Duration Continuous AE Activity HILDCAAs on the equatorial ionosphere in the Brazilian region during the periods of 27-31 March 2001 and 12-16 April 2004. The following experimental data were used here: 1 . Ionospheric parameters h'F, hmF2 and foF2 obtained from ground-based either Digisonde or digital ionosonde located at São Luís (2,33S; 44,2W, dip 1.6S epoch 2001), Fortaleza ( $3^{\circ} 53^{\prime} \mathrm{S} 38^{\circ} 25^{\prime} \mathrm{W}$ dip $10.9 \mathrm{~S}$ epoch 2001) and Cachoeira Paulista $\left(22^{\circ} 41^{\prime} \mathrm{S}, 45^{\circ} \mathrm{OOW}\right.$, dip 31.8 epoch 2001).2. The auroral indexes $A U, A L$, and $A E$, and the Dst index, and 3. Interplanetary data from the Advanced Composition Explorer/ACE satellite orbiting around Lagrangian L1: north-south magnetic field component $\mathrm{Bz}$, solar wind velocity $\mathrm{V}_{\mathrm{H}}$, plasma temperature $T_{H}$, and electric field.

\section{Introduction}

Tsurutani and Gonzalez (1987, 2004) empirically defined the HILDCAAs events as a continuous sequence of high intensity $A E$ index for extended periods of time from a few days to weeks, in which the AE index never ranges below 200nT for more than two continued hours, present peaks over 1000nT and occur outside the main phases of magnetic storms. The reason for being outside storm main phases, they claim, is the lack of experimental/theoretical evidence in support of storm recoveries durations of days or weeks.

Although the ionospheric storm effects have been extensively studied over the Brazilian region (Abdu et al., 1988, 1990, 1993, 1995, 2003; Sobral et al., 1997, 2001) the effects of the HILDCAAs have not.
The purpose of this work is to investigate the effects of the HILDCAAS in the ionospheric F region over Brazil by means of ground ionosonde/Digisonde data obtained in the following periods: 27 - 31 March, 2001 and $12-16$ April, 2001. This abstract will very briefly show the main points of this study.

\section{Method}

The basic method of the present analysis is the comparison of the behavior of ionospheric parameters hmF2 (height of the maximum electron density), h'F (height of the base of the F-layer) and foF2 (critical frequency of the F2 layer) during the quiet and disturbed days. The behavior of those parameters during quiet days is represented by averages of those parameters during three quiet days taken within the period of \pm 15 days centered in the HILDCAAs period. Two equatorial stations (São Luís-SL and Fortaleza-FZ) and one low latitude station (Cachoeira Paulista-CP) were used in this study to help the data interpretation. The large deviations from the quiet mean are regarded here as the disturbed effects (see Sobral et al., 1997). It should be noted that the height of the F-layer base h'F is a better representative of the ionospheric base height when the $F$ layer is situated above $300 \mathrm{~km}$ because below that height recombination impairs the estimation of height variations.

\section{Results and discussionExamples}

The results of this work are presented in Figures 1 and 2 . They contain data obtained during the HILDCAAs events that occurred during 27 - 31 March, 2001 and 12 - 16 April, 2001. Figures 1 and 2 show ionospheric and magnetospheric data for different days. The average values of the parameters hmF2, hpF2, h'F and foF2 are represented by continuous lines and variance bars; the data relative to the HILDCAAs periods are represented by data points. The sequence of dashed narrow rectangles on the upper part of the panel stands for spread-F occurrence. The days of these plots focus the HILDCAAs phenomena and consequently do not present geomagnetic storm signatures except on March 31, 2001. The data points deviations refer to the deviation of the day with respect to the average curve. hmF2 is the real height of electron density peak obtained from Digisondes, $\mathrm{hpF} 2$ is the estimated peak height, $h^{\prime} F$ is the height of the base of the F-layer and foF2 is the cutoff frequency of the $\mathrm{F}$ layer. The interplanetary proton temperature $\mathrm{TH}$, dawnto-dusk e-field (positive in the dawn-to-dusk direction), particle density $\mathrm{NH}$ and north-south magnetic field component $\mathrm{Bz}$ are shown. In all plots the $\mathrm{Bz}$ intensity oscillated around zero nT with high frequency and low 
amplitude as typically induced by interplanetary Alfvén waves. Threshold horizontal lines are put in all figures at $200 \mathrm{nT}$ for the Auroral indexes and the $\mathrm{h}^{\prime} \mathrm{F}=300 \mathrm{~km}$.

\section{7-31 March 2001}

The AE index varied between about 200nT and 1700nT. The Dst curve presented a steady amplitude around -50 $\mathrm{nT}$ up to the fifth day at $\sim 01 \mathrm{LT}$ when a very intense storm started. Ionospheric effects: São Luís: hmF2 presented very large rises from $\sim 12 \mathrm{LT}$ to $\sim 22 \mathrm{LT}$ from the first to the fourth day. The fifth day contains a strong storm effect on the $\mathrm{hm}$ parameter (high amplitude and long duration rises). Fortaleza: $\mathrm{hm}$ raised above the average curve similarly as São Luís. Cachoeira Paulista (CP): hm was seen to remain above the average curve most of the time. The parameter foF2 presented no particular disturbance at both $\mathrm{FZ}$ and $\mathrm{CP}$.

\section{2-16 April 2001}

The AE index varied between about 200nT and 1800nT. The Dst index steadly increased from -200nT in the beginning of the first day to $-25 \mathrm{nT}$ on the fourth day.

Ionospheric effects: São Luís: hmF2 remained close to the quiet curve most of the time. Fortaleza: $\mathrm{hm}$ raised above the average on the 14th day generating spread $F$. On the other days the hmF2 parameter remained very close to the quiet values. Cachoeira Paulista (CP): hmF2 remained quiet most of the time expect on the $12^{\text {th }}$ where a large rise was possibly caused by disturbed equatorward winds. Such a rise is also seen on the other two stations SL and SL and seems to be related to a magnetic storm rather that the HILDCAA.

\section{Conclusions}

The main conclusions of this study about the HILDCAAs effects in the low-latitude and equatorial ionosphere over the Brazilian region are: 1 . Figures 1 shows that the Flayer peak height hmF2 at the equatorial station suffer rises during both daytime and nighttime during the occurrence of continued intense AE activity. 2. Both São Luis and Fortaleza stations presented daytime rises of $\mathrm{hpF} 2$, for the 27-31 April period. Such an unusual rise was not observed in the period of 12-16 April 2001. 3. The critical frequency of the $F$ layer foF2 suffers no remarkable changes during the HILDCAAs, both at the low-latitude and equatorial stations, 4. Remarkable simultaneous equatorial and low-latitude rise of the F2 layer such as those occurring during stormtime prompt penetration of electric fields, were not observed. 5. Direct effects of the variations of the interplanetary proton temperature $\mathrm{TH}$, dawn-to-dusk e-field, particle density $\mathrm{NH}$ and north-south magnetic field component $\mathrm{Bz}$ were hardly detected. 6 . In spite of the intense $A E$ activity spread $F$ was often observed at the equatorial station São Luis, which shows that the equatorward disturbed winds were not strong enough to inhibit the rise of the F-layer.

\section{Acknowledgments}

This work was partially supported by the Brazilian funding institutions Conselho Nacional de desenvolvimento Científico e Tecnológico-CNPq and Fundação de Amparo à Pesquisa do Estado de São Paulo (Grants 04/03388-0 IC Isabela G; Barbosa, 03/08778-9IC-R. L. da Silva; 00/00250-7, Daniela. C S. Arruda).

\section{References}

Abdu, M. A., Reddy, B. M., Walker, G. O., Hanbaba, R., Sobral J. H. A., Fejer, B. G., Woodman, R. F., Schunk, R. W., Szuszczewicz, E. P., 1988, Processes In The Quiet And Disturbed Equatorial Low Latitude Ionosphere: Sundial Campaign 1984, Ann. Geophys., 69( T1), 69-80.

Abdu, M. A., Walker, G. O., Reddy, B. M., Sobral, J. H. A., Fejer, B. G., Kikuchi, T., Trivedi, N. B. Szuszczewicz, E. P., 1990, Electric field versus neutral wind control of the equatorial anomaly under quiet and disturbed conditions: a global perspective from SUNDIAL 86, Ann. Geophys., 8, 419-430.

Abdu, M. A., Walker, G. O., Reddy, B. M., De Paula, E. R., Sobral, J. H. A., Fejer, B. G., Szuszczewicz, E. P., 1993, Global Scale Equatorial Ionization Anomaly (EIA) Response To Magnetospheric Disturbances Based On The May-June 1987 Sundial Observations, Ann. Geophys., 11, 585-594.

Abdu, M. A., Batista, I. S., Walker, G. O., Sobral, J. H. A., Trivedi, N. B. and De Paula, E. R., 1995, Equatorial ionospheric electric fields during magnetospheric disturbances: local time/longitudinal dependencies from recent EITS campaigns, J. Atmos. Terr. Phys. 57, 10651083.

Abdu, M. A., Batista, I. S., Takahashi, H., McDougall, J., Sobral, J. H. A. Medeiros, A. F., Trivedi, N. B., 2003, Magnetospheric Disturbance Induced Equatorial Plasma Bubble Development And Dynamics: A Case Study In Brazilian Sector, J. Geophys. Res., 108(A2), 1449, Doi:10.1029/2002ja009721.

Sobral, J. H. A, Abdu, M. A., Gonzalez, W. D., Tsurutani, B., T. and Batista, I. S., 1997, Effects of Intense Storms and Substorms on the Equatorial Ionosphere/Thermosphere System in the American Sector from Ground Based and Satellite Data: J. Geophys. Res., 102(A7), 14305-14313.

Sobral, J. H. A, Abdu, M. A., Yamashita, C. S., Gonzalez, W. D., Gonzalez, A. C., Batista, I. S., Zamlutti, C. J., Tsurutani, B., T., 2001, Responses Of The Low-Latitude Ionosphere To Very Intense Geomagnetic Storms, J. Atmos. Terr. Physics, Vol. 63, No.9, 965-974.

Tsurutani, B.T. and W.D. Gonzalez, 1987, The cause of high-intensity long-duration continuous $A E$ activity (HILDCAAs): interplanetary Alfvén wave trains: Planetary and Space Science 35, p. 405-412. 
Tsurutani, B.T., Gonzalez, W. D.,Guarnieri, F., Kamide, Y., Zhou, X, and Arballo, J. K., 2004, Are high-intensity long-duration continuous AE activity (HILDCAA) events substorm expansion events?: Journal of Atmospheric and Solar-Terrestrial Physics, Volume 66(2), 167-176.

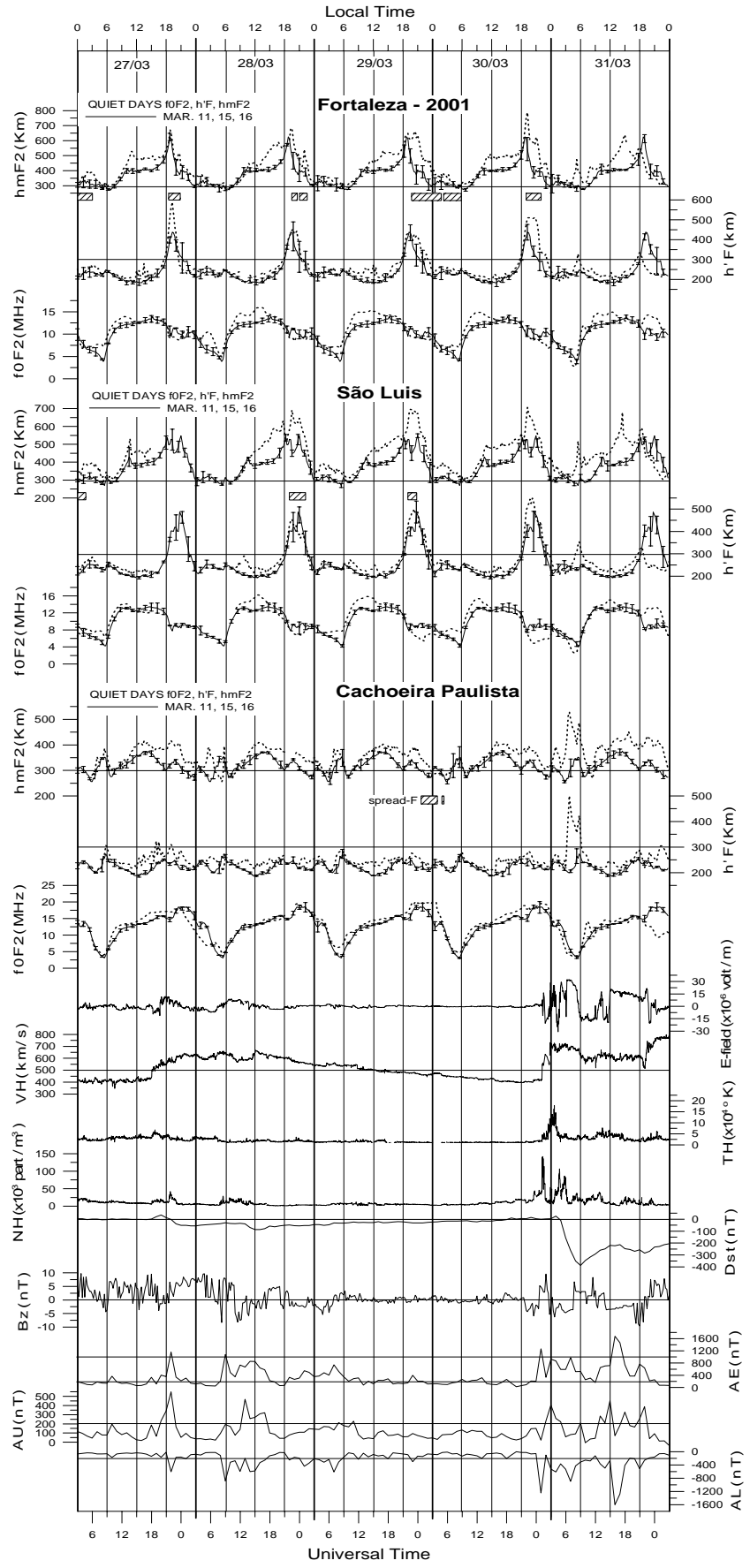

Figure 1. Time variation of the ionospheric parameters h'F, hpF2, and foF2, during HILDCAAs, where h'F is the virtual height of the base of the F-layer, hpF2 is the estimated height of the peak of the F-layer from a parabolic approximation of the peak height and foF2 is the F-region critical frequency, both for Fortaleza (Geogr. 3.8S, 38W and dip 2.5S for the epoch of 1979) and
Cachoeira Paulista (Geogr. 22.41S, 45W, and dip 25.7S for the epoch of 1979). The quiet days used in the reference curve are indicated in the top left-hand side of the figure. Also shown is the time evolution of the auroral elecrojet index $\mathrm{AE}$, the storm-time disturbance index Dst, the Interplanetary electric field, temperature, density and the vertical component of the interplanetary magnetic field $\mathrm{Bz}$, as obtained by in-situ by the Interplanetary Sun-Earth Explorer-ISEE3 satellite.

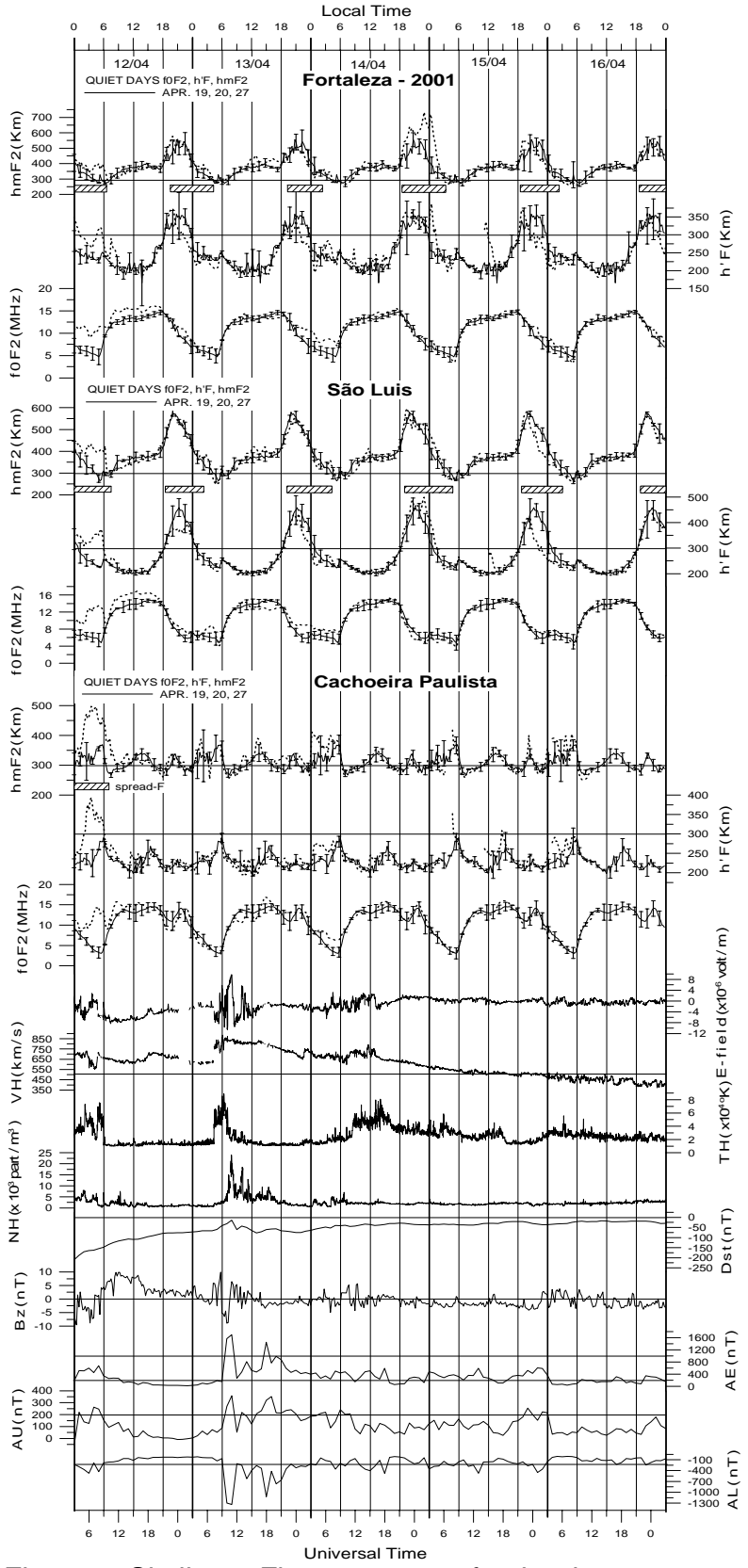

Figure 2. Similar to Figure 1 except for the dates. 

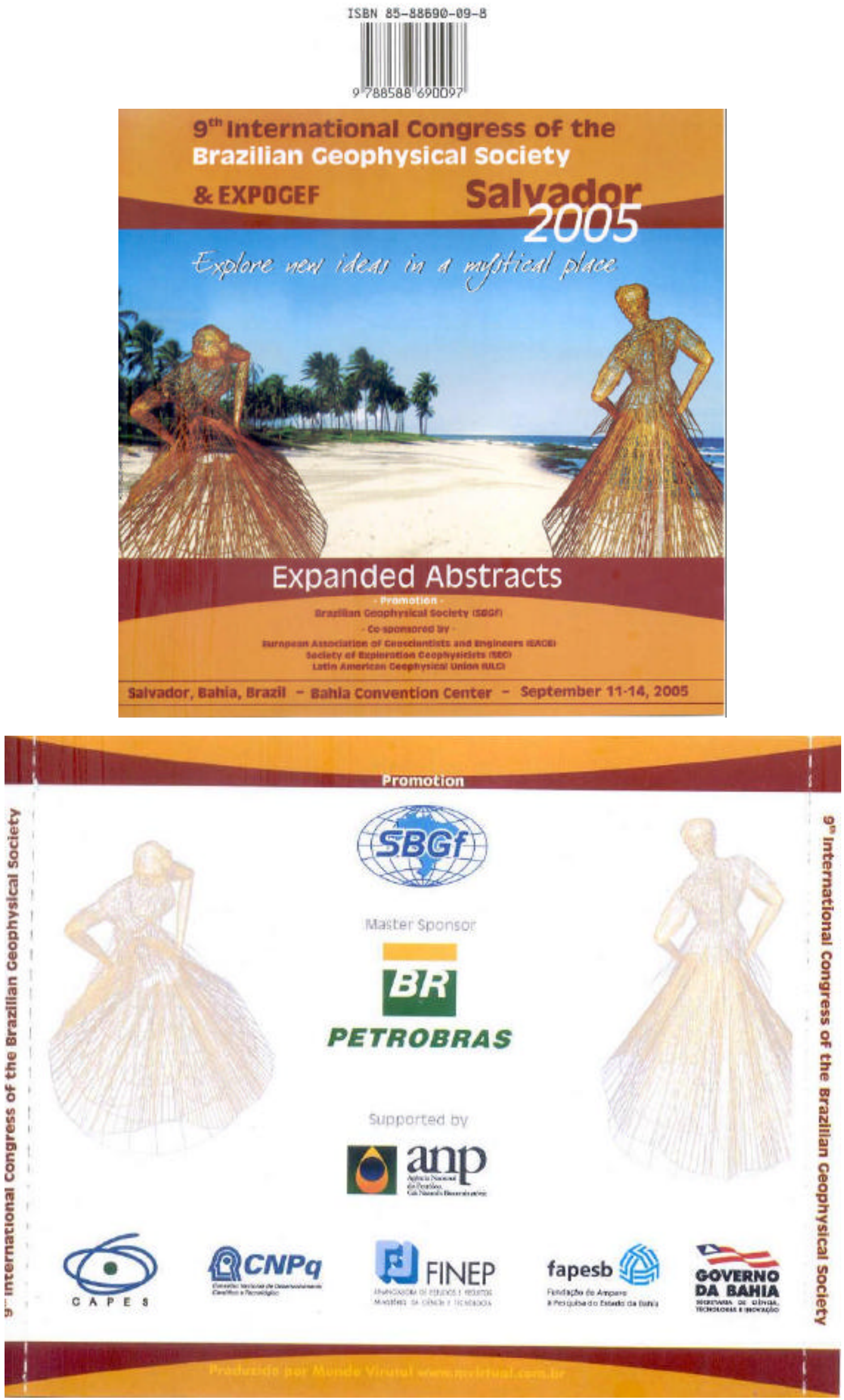